\title{
COVID-19 and alcohol consumption: were mariners forgotten?
}

\author{
Richard Pougnet ${ }^{1,2,3}{ }^{\oplus}$, Samia Mahani ${ }^{3}$, Laurence Pougnet ${ }^{1,4}{ }^{(}$, \\ David Lucas $^{1,5}$, , Morgane Guillou ${ }^{3,6}$, Brice Loddé ${ }^{1,5}$ \\ ${ }^{1}$ French Society of Maritime Medicine, France \\ ${ }^{2}$ Laboratoire d'Etudes et de Recherche en Sociologie (LABERS), EA 3149, European University of Brittany, Brest, France \\ ${ }^{3}$ Medicine Faculty, Department of Therapeutic Education and Addictology, European University of Brittany, Brest, France \\ ${ }^{4}$ Military hospital, Clermont-Tonnerre, French Army, Brest, France \\ ${ }^{5}$ Physiology Research Unit (ORPHY), EA 4324, European University of Brittany, Brest, France \\ ${ }^{6}$ Addiction Unit, Teaching Hospital, Brest, France
}

More than 1 year after, coronavirus disease 2019 (COVID-19) pandemic is still on with high impact on social relationship. Measures to protect against the virus limit capacities and modalities of time spending in family, with friends or in working groups. In April 2021, worldwide total deaths due to COVID-19 are more than 3 million. Maritime transport decreased of $4 \%$ in 2020 . Seafarers are impacted on different ways: travel restrictions have meant that they cannot leave their ships, be repatriated home or even receive urgent medical assistance. Other seafarers have seen their contracts unilaterally terminated or been quarantined on board their vessels for more than 14 days, all without pay. What about health impact for seafarers?

We could answer by different ways. We only discuss alcohol consumption in this letter. Indeed, it is well known that alcohol consumption, addiction and mental health burden linked to it are real problems in this population [1]. Is the COVID-19 modifying it? It's impossible to answer when looking on data in recent literature.

However, it was demonstrated for other working groups. Some studies found a decrease in alcohol consumption as in China with restrictions on movement [2]. In other way, due to fewer situations of parties, teenagers and young adults limited their binge drinking habits [3]. Nevertheless, in most of studies, alcohol consumption increased during the COVID-19 pandemic, especially in United Kingdom, Australia or European Union. Reasons are numerous [4-6]. For some, they used alcohol as an anxiolytic and during the pandemic, information from media was a strong risk factor for anxiety. For others, restriction of movement highlighted some problems with their family, and they wanted to forget it. And finally, some people used alcohol to overcome boredom. The lack of sport and professional activity increased feelings of monotony and uselessness [6].

Linked to these elements, seafarers would probably have such social problems. During longer period ashore, they had to adapt to new conditions of life with higher social demand from their families. During embarkment, on the one hand work tasks could be an escape from new social balance, and on the other hand they were more anxious with news on the pandemic. Symptoms of anxiety could increase when seafarers stayed in port of high COVID-19 impacted countries or if some of their social relations lived in such countries.

For this population with higher prevalence of psychoactive substances consumption, conditions due to COVID-19 pandemic strengthened the need of prevention of alcohol consumption or other addiction. Risk assessment and preventive interventions for this population should be a relevant and important axis of public health.

\section{REFERENCES}

1. Pougnet R, Pougnet L, Loddé $B$, et al. Consumption of addictive substances in mariners. Int Marit Health. 2014; 65(4): 199-204, doi: 10.5603/IMH.2014.0038, indexed in Pubmed: 25522703.

2. Wang $\mathrm{Y}, \mathrm{Lu} \mathrm{H}, \mathrm{Hu} \mathrm{M}$, et al. Alcohol consumption in china before and during COVID-19: preliminary results from an online retrospective survey. Front Psychiatry. 2020; 11: 597826, doi: 10.3389/ fpsyt.2020.597826, indexed in Pubmed: 33324263. 
3. Bollen Z, Pabst A, Creupelandt C, et al. Prior drinking motives predict alcohol consumption during the COVID-19 lockdown: A cross-sectional online survey among Belgian college students. Addict Behav. 2021; 115: 106772, doi: 10.1016/j.addbeh.2020.106772, indexed in Pubmed: 33418433.

4. Tran TD, Hammarberg K, Kirkman M, et al. Alcohol use and mental health status during the first months of COVID-19 pandemic in Australia. J Affect Disord. 2020; 277: 810-813, doi: 10.1016/j. jad.2020.09.012, indexed in Pubmed: 33065821.
5. Garnett C, Jackson S, Oldham M, et al. Factors associated with drinking behaviour during COVID-19 social distancing and lockdown among adults in the UK. Drug Alcohol Depend. 2021; 219: 108461, doi: 10.1016/j.drugalcdep.2020.108461, indexed in Pubmed: 33454159.

6. Schmits E, Glowacz F. Changes in alcohol use during the COVID-19 pandemic: impact of the lockdown conditions and mental health factors. Int J Ment Health Addict. 2021 [Epub ahead of print]: 1-12, doi: 10.1007/s11469-020-00432-8, indexed in Pubmed: 33424513. 